\title{
Anthropometric characteristics and physical performance of taekwondo athletes
}

\section{Características antropométricas e desempenho físico de Iutadores de taekwondo}

\author{
Andressa Formalioni ${ }^{1}$ \\ (D) https://orcid.org/0000-0002-2277-9997 \\ Bruno Fernandes Antunez ${ }^{2}$ \\ (1D) https://orcid.org/ 0000-0002-3162-6466 \\ Fabrício Boscolo Del Vecchio ${ }^{3}$ \\ (D) https://orcid.org/0000-0003-3771-9660 \\ Léo Dutra Cabistany ${ }^{3}$ \\ (D) https://orcid.org/ 0000-0002-6338-2208 \\ Victor Silveira Coswig 4 \\ (D) https://orcid.org/0000-0001-5461-7119 \\ Rubens Vinícius Letieri² \\ (D) https://orcid.org/0000-0003-4520-6339 \\ David H Fukuda ${ }^{5}$ \\ (D) https://orcid.org/0000-0002-4299-7764
}

\begin{abstract}
The purpose of this investigation was to measure anthropometric and physical performance variables of TKD athletes from the city of Pelotas - RS. Forty-five athletes aged $16.4 \pm 5.2$ years and time of practice of $3.25 \pm 3.6$ years were evaluated. Athletes performed anthropometric evaluation and physical, general and specific performance tests. In the sum of seven skin folds, men presented lower values $(106.1 \pm 49.5 \mathrm{~mm}$ versus $143.4 \pm 43.2 \mathrm{~mm}, \mathrm{p}$ $<0.002)$. Male seniors presented better performance in the vertical jump compared to beginners $(42.3 \pm 8.5 \mathrm{~cm}$ versus $24.8 \pm 10.1 \mathrm{~cm}, \mathrm{p}<0.03)$ and to women $(22.1 \pm 4.3 \mathrm{~cm}, \mathrm{p}<0.03)$. Graduated individuals perform higher number of arm pushups than beginners and women and more repetitions in the abdominal test. Male junior and senior athletes had higher isometric handgrip strength than females $(48.3 \pm 3.9 \mathrm{kgf}$ and $38.1 \pm 12.6 \mathrm{kgf}$ versus $29 \pm 5.6 \mathrm{kgf}, \mathrm{p}$ $<0.001)$. Men covered longer distance in the yo-yo test than women $(606.6 \pm 233.8 \mathrm{~m}$ versus $200 \pm 113.1 \mathrm{~m}, \mathrm{p}<0.001)$. In the Wingate test, men produced greater peak and average relative power. No differences in flexibility were observed. In the single kick test, seniors kicked faster than less experienced athletes $(200.6 \pm 12.3 \mathrm{~m} / \mathrm{s}$ versus $258 \pm 5.6 \mathrm{~m} / \mathrm{s}, \mathrm{p}<0.001)$ and performed greater number of kicks in the $21 \mathrm{~s}, 6 \pm 2.1$ reps versus $15.5 \pm 0.7$ reps, $\mathrm{p}<0.001$ ). It was concluded that there are differences between male and female TKD athletes regarding anthropometric and motor characteristics, and that more experienced athletes exhibit greater general and specific physical fitness.
\end{abstract}

Key words: Body Composition; Martial Arts; Physical education and training.

Resumo - O objetivo desta investigação foi mensurar variáveis antropométricas e de desempenho físico de atletas de TKD da cidade de Pelotas - RS. Foram avaliados 45 atletas com idades 16,4 5, 2 anos e tempo de prática de 3,25 3,6 anos. Os atletas realizaram avaliação antropométrica, testes de desempenho físico, gerais e especificos. No somatório de sete dobras cutâneas, homens apresentam menores valores $(106,1 \pm 49,5 \mathrm{~mm}$ versus $143,4 \pm 43,2 \mathrm{~mm} ; \mathrm{p}<0,002)$. Homens mais graduados apresentaram melhor desempenho no salto vertical que homens iniciantes $(42,3 \pm 8,5 \mathrm{~cm}$ versus $24,8 \pm 10,1 \mathrm{~cm}$; $p<0,03)$ e que mulheres $(22,1 \pm 4,3 \mathrm{~cm} ; p<0,03)$. Individuos graduados realizam maior número de flexôes de cotovelo que iniciantes e mulheres e mais repetiçôes no teste de abdominais. Atletas da categoria sênior ejúnior masculino exibiram mais força isométrica de preensão manual que as mulheres $(48,3 \pm 3,9 \mathrm{kgf}$ e $38,1 \pm 12,6 \mathrm{~kg} f$ versus $29 \pm 5,6 \mathrm{~kg} f ; p<0,001)$. Homens percorreram maior distância no yo-yo test que mulheres $(606,6 \pm 233,8 \mathrm{~m}$ versus $200 \pm 113,1 \mathrm{~m} ; \mathrm{p}<0,001)$. No teste de Wingate, homens produziram maior potência relativa máxima e média. Não foram observadas diferenças na flexibilidade. No teste de chute único, individuos mais graduados chutaram mais rápido do que os menos graduados $(200,6 \pm 12,3 \mathrm{~m} / \mathrm{s}$ versus $258 \pm 5,6 \mathrm{~m} / \mathrm{s} ; p<0,001)$ e executam maior número de chutes em 10 s $(21,6 \pm 2,1$ reps versus $15,5 \pm 0,7$ reps; $p<0,001)$. Conclui-se que há diferenças entre homens e mulheres praticantes de TKD quanto a caracteristicas antropométricas e motoras, e que atletas mais avançados exibem maior aptidão física geral e especifica.

Palavras-chave: Artes marciais; Composição corporal; Educação física e treinamento.
1 University of São Paulo. School of Physical Education and Sport. São Paulo-SP. Brazil

2 Federal University of Tocantins. School of Physical education. Tocantinópolis, TO. Brazil

3 Federal University of Pelotas. School of Physical Education. Pelotas, RS. Brazil

4 Federal University of Pará. School of Physical Education. Castanhal, PA. Brazil

5 University of Central Florida. School of Kinesiology and Physical Therapy. Orlando, FL. United States of America

Received: March 08, 2018 Accepted: May 29, 2019

How to cite this article Formalioni A, Antunez BF, Del Vecchio FB, Cabistany LD, Coswig VS, Letieri RV, Fukuda DH. Anthropometric characteristics and physical performance of taekwondo athletes. Rev Bras Cineantropom Desempenho Hum 2020, 22:e55697. D0l: http://dx.doi. org/10.1590/1980-0037.2020v22e55697

Copyright: This work is licensed under a Creative Commons Attribution 4.0 International License. 


\section{INTRODUCTION}

Taekwondo (TKD) is an official combat modality of the Olympic Program ${ }^{1}$, and is also part of the Youth Olympic Games program for competitors aged 14-18 years, with five weight categories for each sex. Most studies on TKD are aimed only at general indicators of physical fitness ${ }^{1,2}$. In this context, measurements of anthropometric aspects, strength resistance and muscular power measured by vertical jumps ${ }^{1}$ or measured in isokinetic dynamometer ${ }^{2}$ are common. From the point of view of the specific evaluation, a recent study described the profile of elite Brazilian athletes in the 10 -s kick test ${ }^{1}$. Knowledge on specific fitness is necessary for the proper organization of the training processes, since this is relevant for the good performance in the modality. In TKD, ectomorph profile, lower limb power, as well as well-developed aerobic resistance and anaerobic power are required ${ }^{2,3}$. In general, athletes of both sexes with higher graduation have higher maximum oxygen uptake $\left(\mathrm{VO}_{2} \max \right)$ and lower fat percentage when compared to less graduated athletes ${ }^{4}$. When comparing age groups, it was observed that younger recreational athletes have lower $\mathrm{VO}_{2}$ max compared to older athletes ${ }^{5}$. However, there is still lack of evaluations considering aspects such as level of experience and sex.

Studies have pointed out that high physical fitness is relevant for success in $\mathrm{TKD}^{1,3-4}$. This occurs because in a single championship, there are successive matches, which are structured in fights of two to three rounds from 90 s to 120 s, with rests of 60 s, with intermittent and high-intensity efforts ${ }^{6}$. Since the physical conditioning of TKD athletes is considered as one of the main factors for success in competitive performance ${ }^{1}$, the scoring system involves the application of blows to the opponent's trunk and head in high-speed motor actions that generate impacts sufficiently strong to validate the points obtained ${ }^{6}$. As competitions are divided by age, sex and graduation, knowing the physical fitness of TKD athletes from these parameters can contribute to better description of the sporting profile and better knowledge of the sport's demands ${ }^{1}$.

It is noteworthy that the greater the speed and power of blows of a fighter, the greater the chances of competitive success ${ }^{6}$. In this sense, the study hypothesis is that sex, age and experience differently affect general anthropometry and physical fitness aspects, while experience and graduation would have greater effect on specific aspects of the modality. Considering the scarcity of studies comparing the general and, mainly, the specific performance of TKD athletes, the aim of this investigation was to evaluate anthropometric variables and general and specific physical performance in TKD athletes according to sex, age group and level of experience.

\section{METHOD}

This is a cross-sectional observational study. Athletes and their legal guardians read and signed a free and informed consent form and the study was 
approved by the local ethics committee on research with human beings (protocol \# 445.796/2013). To carry out the study, forty-five TKD athletes were included: beginners (from the $9^{\text {th }}$ to the $4^{\text {th }}$ gub) and graduates (above the $3^{\text {rd }}$ gub) of both sexes from a municipality in southern Brazil. After clarifications and agreement for participation was obtained, participants scheduled specific days and times for participation in the study. The sample recruitment process took into account accessibility, and all fitness centers and clubs with TKD practices in the city were visited and invited to participate.

Each individual was evaluated in two sessions separated by 72 hours, which took place during the afternoon, two weeks before the main state competition in the first semester of 2014. The same times were scheduled for all individuals, and procedures took place between 02:00 pm and 07:00 $\mathrm{pm}$. To perform physical tests, the five-minute warm-up routine started, consisting of low-intensity run (Borg's subjective perception of effort scale between 13 and 14). Later, athletes went to the collection area, which took place in the sport dojan, which was organized for this purpose.

In the first session, anthropometric measurements were performed, followed by warm-up and then strength assessments and anaerobic power test. In the second session, aerobic power, lower limb power and kick speed tests were performed. Each evaluation was carried out by the same and single evaluator, and the data collection team was previously trained. Data were recorded in specific individual forms and later transferred to spreadsheets. The following evaluation procedures were adopted:

\section{Anthropometry}

Body mass measurement occurred with subjects wearing only trunks and Tshirt (Toledo ${ }^{\circledR}$ platform scale with $0.05 \mathrm{~kg}$ precision). Height was measured with bare feet on stadiometer attached to the scale. Skin folds (SF) were measured with scientific adipometer $\left(\mathrm{Cescorf}^{\circledR}\right.$, previously measured and calibrated) with $0.1 \mathrm{~mm}$ precision, according to protocol of Jackson and Pollock ${ }^{7}$. The thickness of pectoral, medioaxillary, triceps, subscapular, abdomen, supra-iliac and thigh SFs was measured. All skin folds were measured three times on the individual's right side and in a rotation system.

\section{General physical performance tests}

\section{- Muscle power of lower limbs (in cm)}

Evaluated with vertical jump test (VJ) with counter movement, using contact mat (Jump System Pro ${ }^{\circledR}$, CEFISE, Nova Odessa, Brazil). The subject should try to reach the highest height possible while keeping knees and hips extended during the flight phase and hands on waist. Three attempts were allowed for each individual, considering the best result in the analyses. This test has high reproducibility ${ }^{8}$, with $\mathrm{r}$ greater than 0.86 .

\section{- Strength resistance (maximum number of repetitions)}

Trunk flexion, with abdominal test, and elbow flexion tests were performed for men with their feet on the floor and women with their knees. In both 
tests, subjects were instructed to perform as many repetitions as possible in the 60-second period until exhaustion and only correct executions were considered valid. The standardization of both procedures followed specific indications?

\section{- Anaerobic power and capacity and fatigue index}

The Wingate test was used for lower limbs with load of $0.087 \mathrm{kp} / \mathrm{kg}$ of body mass for males and $0.086 \mathrm{kp} / \mathrm{kg}$ for females ${ }^{10,11}$. The peak power in the 30-second test was considered the anaerobic power, the average power represents the anaerobic capacity and both are presented in absolute mode and relative to body mass. The fatigue index for this test results from the value obtained for peak power, subtracted from the lowest power reached during the test multiplied by one hundred and divided by the peak power. This test shows test-retest reproducibility from 0.88 to 0.99 , with values frequently above 0.94 according to Franchini ${ }^{10}$. BIOTEC $2100^{\circledR}$ cycle ergometer (CEFISE, Nova Odessa, Brazil) was used.

\section{- Aerobic power (in m)}

Evaluated with level 1 intermittent YO-YO test, and athletes performed, for as long as possible and in a back and forth regime, 20-meter straight runs. Speed was controlled by sound signals produced with standard audio of the protocol and the test was ended when the participant was unable to follow the rhythm imposed by sound signals twice consecutively ${ }^{12}$. As final result of the test, the total number of meters covered by the athlete up to the last run correctly performed was recorded. The distance covered in the $\mathrm{Yo}_{\mathrm{o}}$-Yo test was transformed into $\mathrm{VO}_{2}$ max using the $\mathrm{VO}_{2}$ max equation $(\mathrm{ml} / \mathrm{kg} / \mathrm{min} /)=$ distance $(\mathrm{m}) \times 0.0084+36.4$. This test has high reproducibility $(r=0.98)$ for athletes in intermittent sports ${ }^{11}$.

\section{- Flexibility test (cm)}

The Wells bench (Sanny ${ }^{\circledR}$, São Paulo, Brazil) was used, and the result was measured from the most distant position that the athlete could reach on the scale with fingertips. The best result was recorded among three executions with annotation to one decimal place ${ }^{12}$.

\section{- Isometric handgrip strength (kgf)}

Isometric handgrip strength was bilaterally evaluated, three times consecutively, with JAMAR ${ }^{\circledR}$ hydraulic dynamometer, considering the highest value of each hand ${ }^{7}$. To perform the test, subjects remained seated, with $90^{\circ}$ elbow flexion.

\section{Specific physical performance tests}

\section{- Kicking frequency (maximum number of repetitions)}

The greatest number of kicks on a fixed target (30 kg punching bag) with the dominant leg in a period of ten seconds was recorded ${ }^{13,14}$. The test, called Frequency speed of kick test (FSKT) was performed with subject at self-selected distance from the target. Higher execution speed was re- 
quested in each kick, and this evaluation shows test-retest reproducibility greater than $0.76^{13}$.

\section{- Kicking time (in ms)}

The Bandal Tchagui (BT) kick time was measured with the back leg at distance measured under the width of a fighting base between the athlete's front foot and the target. To quantify the application time of kicks, a digital camera (Casio ${ }^{\text {TM }}$, model EX-ZR100) was used, which shoots in Full HD using a $240 \mathrm{fps}$ module and analysis in the Kinovea software, as previously conducted and suggested ${ }^{15}$.

For statistical analysis, after determining data normality with the Shapiro-Wilk test, data are presented as mean \pm standard deviation (SD). For comparisons between means, three-way analysis of variance was applied (ANOVA 3-way: age category (cadet, junior and senior) x sex (male and female) $\mathrm{x}$ graduation (beginner and experienced). To estimate the effect size (ES), partial eta-squared $\left(\eta^{2} \mathrm{p}\right)$ values are presented, which are classified as small (0.01), medium (0.06) and large (0.14). When significant differences were found, post-hoc Bonferroni was used. Statistical significance was determined when $\mathrm{p}<0.05$ and the SPSS 17.0 software was used in routine analyses.

\section{RESULTS}

Forty-five athletes were evaluated, 12 women and 33 men aged $16.4 \pm 5.2$ years and time of practice of $3.2 \pm 3.5$ years. Of these, $15.6 \%$ were black belts and $84.4 \%$ were colored belts, with $20 \%$ of them black belt candidates. The anthropometric characteristics of athletes are shown in table 1 and indicate that body mass and height are higher in athletes in the senior category.

In the vertical jump test, differences between sex and graduation are identified, but without interactions, which allows indicating that men

Table 1. Anthropometric characteristics of Taekwondo athletes according to sex and level of experience $(\mathrm{N}=45)$.

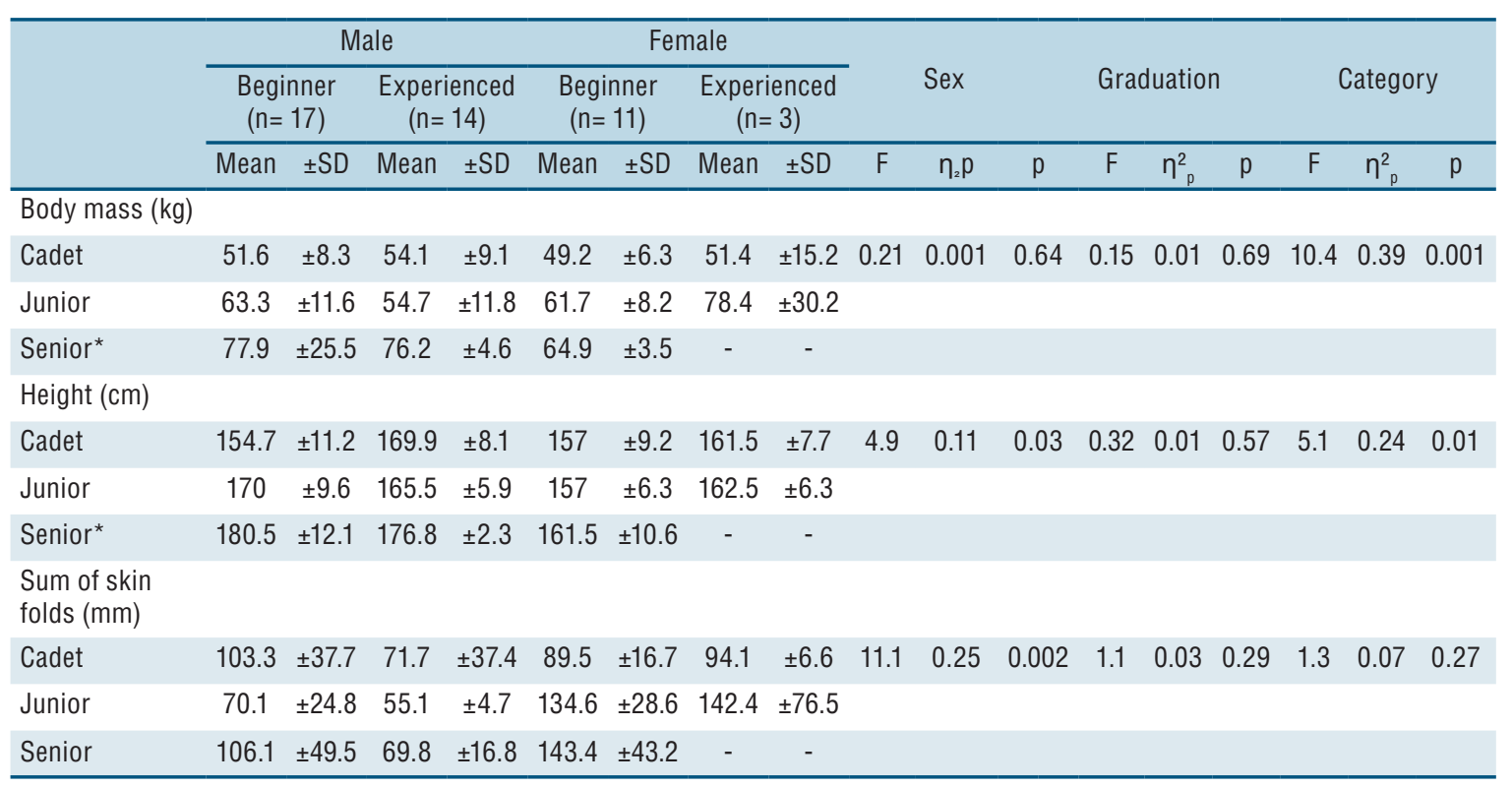

Note. * Statistical difference when compared to the cadet category $(p<0.05)$. SD $=$ standard deviation. 
jump higher than women $(\mathrm{p}=0.003)$ and experienced athletes jump higher than beginners $(p=0.02$; table 2$)$. In the elbow flexion test, difference was found between graduations, with the highest values among more graduated athletes. For abdominal pushups, differences were observed between sexes $\left(F=8.01 ; \eta^{2} \mathrm{p}=0.20 ; \mathrm{p}=0.008\right)$, and graduations $\left(\mathrm{F}=6.7 ; \eta^{2} \mathrm{p}=0.17, \mathrm{p}\right.$ $=0.01)$, and interaction between sex and age $(p=0.03)$ and between age and graduation ( $p=0.05)$ was observed, which indicates that the age group has important effect on this variable. Regarding anaerobic fitness assessed by the Wingate test, differences between sexes $\left(F=10.3 ; \eta^{2} p=0.24, p=\right.$ $0.003)$ and ages $\left(\mathrm{F}=4.9 ; \eta^{2} \mathrm{p}=0.23, \mathrm{p}=0.01\right)$ were observed at maximum power and men in the senior category have higher values when compared to women in the same category and with athletes in the cadet category. For medium power, difference is observed only between sexes $(F=11.7$; $\left.\eta^{2} \mathrm{p}=0.26, \mathrm{p}=0.002\right)$, and the same is valid for maximum relative power.

For handgrip, statistical difference between sexes $\left(F=15.4 ; \eta^{2} p=\right.$ $0.32, p=0.001)$ and ages $\left(F=8.1 ; \eta^{2} p=0.33, p=0.001\right)$ was observed for the right side and for the left side (sex: $F=14.7 ; \eta^{2} p=0.31, p=0.001$; and ages: $\left.F=8.9 ; \eta^{2} p=0.35, p=0.01\right)$; however, without interaction with graduation, which indicates that the time of practice may not influence handgrip. There were no statistical differences in the flexibility values.

In the maximum aerobic power assessed by the level- 1 intermittent recovery Yo-Yo test, difference was observed only between sexes, with higher values covered by experienced athletes of both sexes. Beginners in the male cadet category reached $38.47 \pm 1.56 \mathrm{ml} / \mathrm{kg} / \mathrm{min}$ and graduates in the same category reached $41.19 \pm 2.07 \mathrm{ml} / \mathrm{kg} / \mathrm{min}$. In females, beginners reached $38.33 \pm 0.57 \mathrm{ml} / \mathrm{kg} / \mathrm{min}$ and graduates reached $38.92 \pm$ $1.18 \mathrm{ml} / \mathrm{kg} / \mathrm{min}$. In the junior category, values are $40.01 \pm 1.81 \mathrm{ml} / \mathrm{kg}$ / min for male beginners, and $41.49 \pm 2.13 \mathrm{ml} / \mathrm{kg} / \mathrm{min}$ for graduates of the same category. In females, $38.16 \pm 1.14 \mathrm{ml} / \mathrm{kg} / \mathrm{min}$ was reached for beginners and $38.08 \mathrm{ml} / \mathrm{kg} / \mathrm{min}$ for graduates. For the senior category, values are $39.08 \pm 1.85 \mathrm{ml} / \mathrm{kg} / \mathrm{min}$ for male beginners and $41.66 \pm 1.18$ $\mathrm{ml} / \mathrm{kg} / \mathrm{min}$ for graduates of the same category. In females, values were $37.40 \pm 0.48 \mathrm{ml} / \mathrm{kg} / \mathrm{min}$ for beginners. Higher maximum oxygen uptake values were found for more graduated male athletes when compared to female athletes $(p<0.05)$.

Figure 1 shows the values of the Wingate test. For maximum anaerobic power $(\mathrm{W})$ variables, statistical differences are observed between sexes $(\mathrm{F}=$ $\left.11.7 ; \eta^{2} \mathrm{p}=0.26 \mathrm{p}=0.003\right)$ and age $\left(F=4.9 ; \eta^{2} \mathrm{p}=0.23, \mathrm{p}=0.01\right)$ without interaction with graduation. For average power, statistical difference was observed between sexes $\left(F=11.7 ; \eta^{2} \mathrm{p}=0.26, \mathrm{p}=0.002\right)$ without interaction between age and graduation. For maximum and relative average power $(\mathrm{W} / \mathrm{kg})$, statistical differences were observed when comparing sexes ( $\mathrm{F}$ $\left.=8.7 ; \eta^{2} \mathrm{p}=0.22, \mathrm{p}=0.006\right)$, with no differences for age and graduation (figure 2). These results indicate that graduation does not seem to affect the power of taekwondo athletes in the present sample.

Table 3 presents the results in specific tests of the modality. For the 
10 -s kick test, there were differences between categories $\left(F=15.5 ; \eta^{2} p=\right.$ $0.32, p=0.001)$, and the same difference was observed in the kick time test $\left(\mathrm{F}=15.17 ; \eta^{2} \mathrm{p}=0.33, \mathrm{p}=0.001\right)$, indicating that more graduated athletes performed better in both tests.

\section{DISCUSSION}

The present study aimed to evaluate anthropometric variables and general

Table 2. General physical performance characteristics of Taekwondo athletes according to sex and level of experience $(N=45)$.

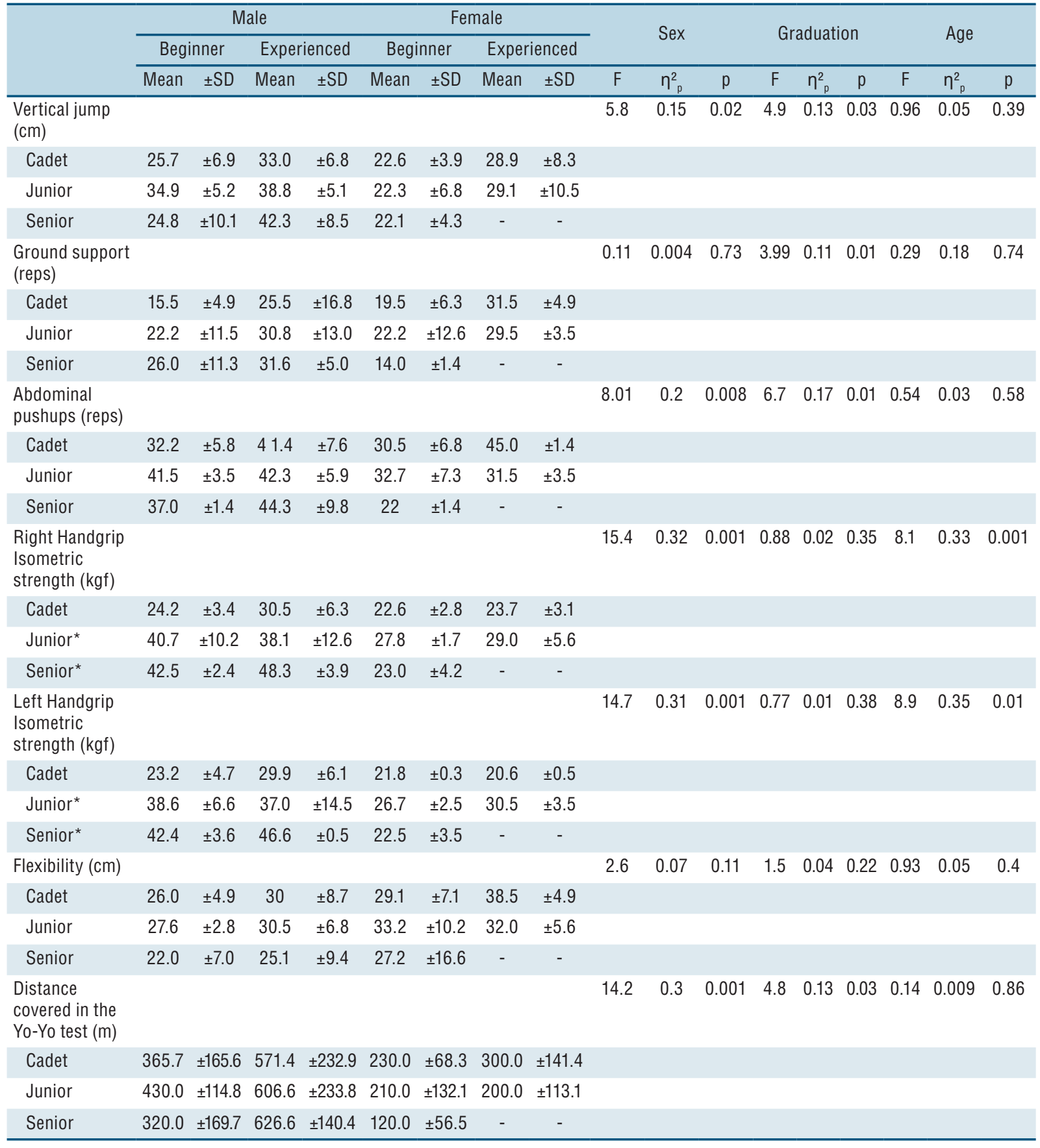

Note. ${ }^{*}$ Statistical difference when compared to the cadet category $(p<0.05)$. SD $=$ standard deviation. 


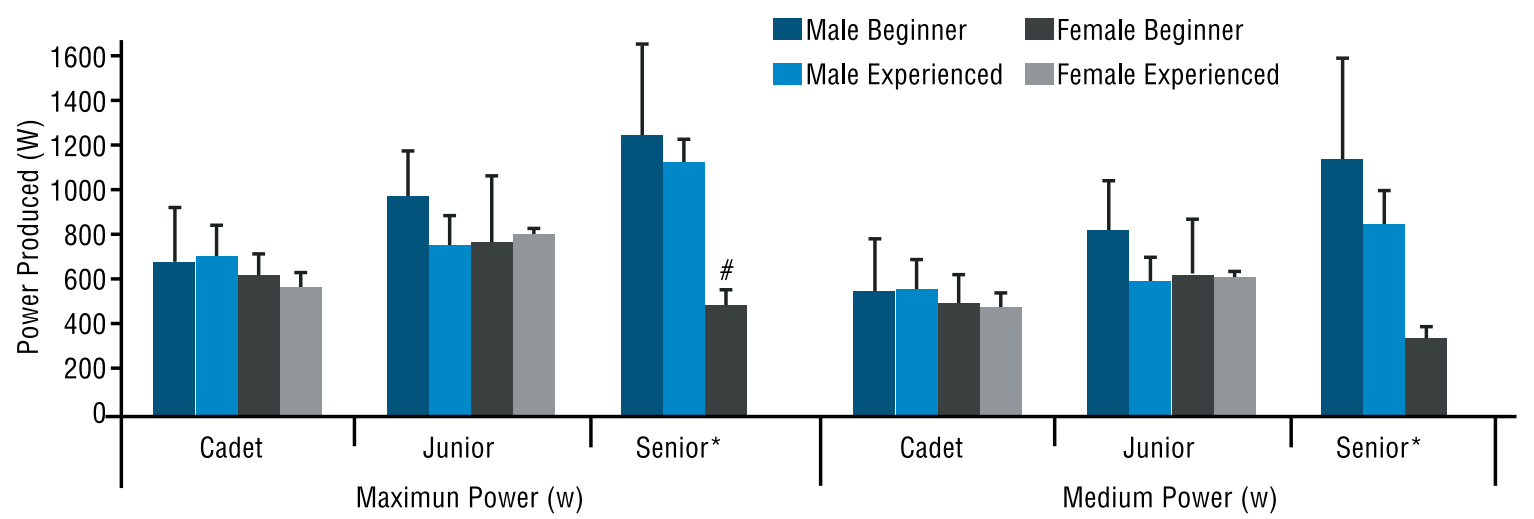

Figure 1. Maximum power and absolute average power in the Wingate test according to category, sex and level of experience.

* Statistical difference when compared to the cadet category $(p<0.05)$. \# Statistical difference when compared to males $(p<0.05)$.

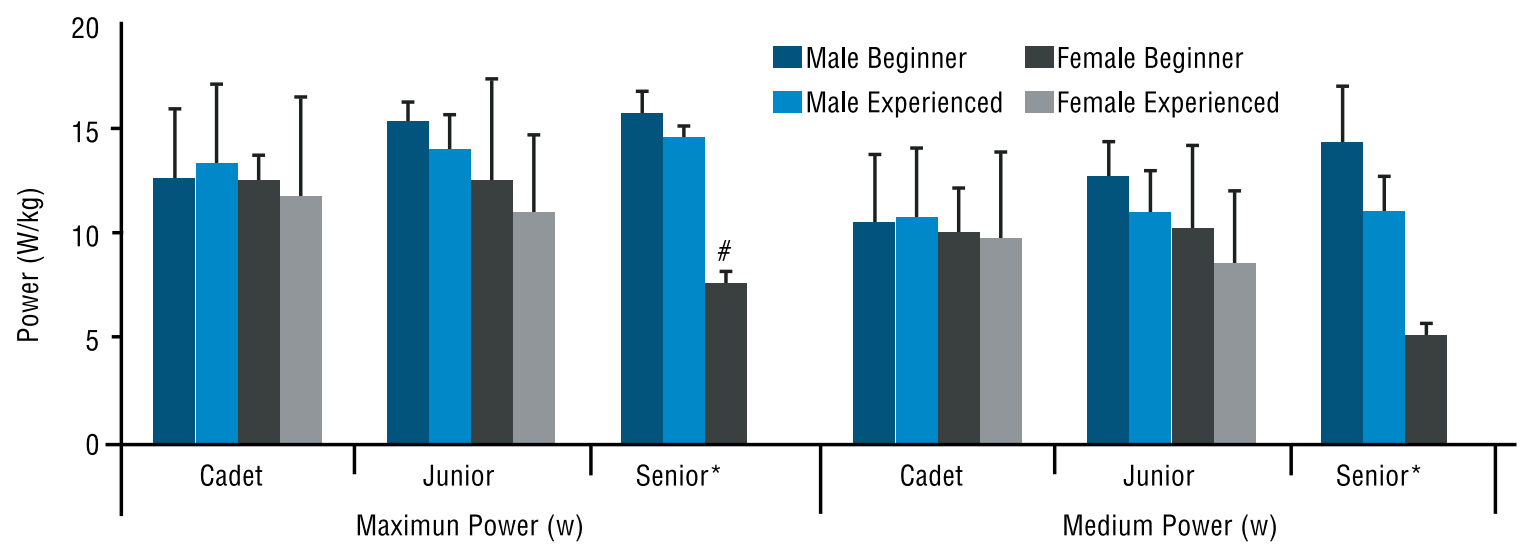

Figure 2. Maximum power and relative average power in the Wingate test according to category, sex and level of experience. \# Statistical difference when compared to males $(p<0.05)$.

Table 3. Specific physical performance characteristics of Taekwondo athletes according to sex, age and level of experience $(N=45)$.

\begin{tabular}{|c|c|c|c|c|c|c|c|c|c|c|c|c|c|c|c|c|c|}
\hline & \multicolumn{4}{|c|}{ Male } & \multicolumn{4}{|c|}{ Female } & \multirow{2}{*}{\multicolumn{3}{|c|}{ Sex }} & \multirow{2}{*}{\multicolumn{3}{|c|}{ Graduation }} & \multirow{2}{*}{\multicolumn{3}{|c|}{ Age }} \\
\hline & \multicolumn{2}{|c|}{ Beginner } & \multicolumn{2}{|c|}{ Experienced } & \multicolumn{2}{|c|}{ Beginner } & \multicolumn{2}{|c|}{ Experienced } & & & & & & & & & \\
\hline & Mean & $\pm \mathrm{SD}$ & Mean & $\pm \mathrm{SD}$ & Mean & $\pm \mathrm{SD}$ & Mean & $\pm \mathrm{SD}$ & $F$ & $\eta_{p}^{2}$ & $p$ & $F$ & $\eta_{p}^{2}$ & $p$ & $F$ & $\eta_{p}^{2}$ & $p$ \\
\hline $\begin{array}{l}10 \text {-s kick } \\
\text { test (reps) }\end{array}$ & & & & & & & & & 0.98 & 0.03 & 0.32 & 15.5 & 0.32 & 0.001 & 0.14 & 0.009 & 0.86 \\
\hline Cadet & 16.0 & \pm 2.0 & 19.2 & \pm 1.1 & 15.2 & \pm 3.8 & 19.0 & \pm 5.6 & & & & & & & & & \\
\hline Junior & 16.7 & \pm 1.7 & 20.0 & \pm 2.0 & 16.5 & \pm 1.2 & 17.0 & \pm 1.0 & & & & & & & & & \\
\hline Senior & 15.5 & \pm 0.7 & 21.6 & \pm 2.1 & 15.5 & \pm 0.7 & - & - & & & & & & & & & \\
\hline $\begin{array}{l}\text { Kick time } \\
(\mathrm{m} / \mathrm{s})\end{array}$ & & & & & & & & & 2.02 & 0.05 & 0.16 & 15.7 & 0.33 & 0.001 & 0.19 & 0.01 & 0.82 \\
\hline Cadet & 254.8 & \pm 28.1 & 233.5 & \pm 15 & 264.2 & \pm 22.9 & 233.0 & \pm 29.6 & & & & & & & & & \\
\hline Junior & 251.7 & \pm 32.5 & 212.6 & \pm 16.7 & 265.2 & \pm 21.4 & 237.0 & \pm 11.3 & & & & & & & & & \\
\hline Senior & 258.0 & \pm 5.6 & 200.6 & \pm 12.3 & 276.5 & \pm 61.5 & - & - & & & & & & & & & \\
\hline
\end{tabular}

Note. $\mathrm{SD}=$ standard deviation

and specific physical performance of TKD athletes and to compare results according to sex and level of experience. Although previous studies have investigated the fitness level of TKD athletes ${ }^{1,15}$ and compared results by $\operatorname{sex}^{16}$, age ${ }^{17}$ or training leve ${ }^{18}$, to the best of our knowledge, this is the first study that considers all these analyses simultaneously. Thus, the main findings reveal that men have differences in relation to women and there 
are also differences between categories in anthropometric and general and specific performance variables. The present study also found that the experience in the modality seems to have an important effect on the performance of specific tests.

The body mass of beginner and experienced cadet athletes of the same category was slightly higher than that found in Israelis of the same category $^{19}$. In Malaysian athletes of national competitive level aged 18 years $^{6}$, values of $68.29 \pm 20.69 \mathrm{~kg}$ were found for male athletes and $59.72 \pm 10.03$ $\mathrm{kg}$ for female athletes, but athletes of the present study presented higher body mass. It was found ${ }^{1}$ that adult male Brazilian elite TKD athletes present average height of $181.67 \pm 8.50 \mathrm{~cm}$, while Malaysian competitors presented $173.90 \pm 8.45 \mathrm{~cm}^{18}$, values close to those found in the present investigation. Regarding body composition, medalists in national and international competitions ${ }^{20}$ were evaluated and the sum of pectoral, axillary, triceps, subscapular, abdomen, supra-iliac and thigh skin folds was $52.4 \pm 12.4 \mathrm{~mm}$. The sum of pectoral, triceps, biceps, subscapular, axillary, abdomen, suprailiac, thigh and calf skin folds of high competitive level athletes was $75.88 \pm 18.20 \mathrm{~mm}$, results similar to the present study with participants of equivalent competitive level. In short, TKD athletes have high stature and low values in the sum of skinfolds, corroborating previous findings about the anthropometric profile for the sport ${ }^{3}$.

Competitive performance in TKD is also associated with lower limb power $^{20}$. In a study carried out with recreational level junior athletes ${ }^{17}$, jump performance was $51.3 \pm 2.8 \mathrm{~cm}$, and in senior athletes, it reached $55.5 \pm 7 \mathrm{~cm}$. In this sense, a previous study compared the vertical jump of female medalists $(32.8 \pm 3.9 \mathrm{~cm})$ and non-medalists $(28.7 \pm 1.9 \mathrm{~cm})$ and found that, on average, medalists jumped $5 \mathrm{~cm}$ more ${ }^{17}$. In the present study, athletes obtained poor performance in the vertical jump test. In females, poor performance in tests involving power can be explained by the fact that, when girls enter the pubertal phase, they tend to increase body fat percentage, while boys increase strength ${ }^{21}$, and the results point for the need to improve this variable in the population under study. The relevance of monitoring and improving the power of lower limbs is highlighted, since it can influence competitive success ${ }^{20}$.

The Wingate test has been used as an indicator of anaerobic fitness, and anaerobic power is relevant in TKD, since the high-intensity actions that determine competitive success, in general, last from 1 to 5 seconds. In this sense, Taaffe et al. ${ }^{22}$ found that in the Wingate test, the absolute and relative maximum power reached by junior male athletes was 675.8 $\pm 30.7 \mathrm{~W}$ and $10.7 \pm 0.3 \mathrm{~W} / \mathrm{Kg}$, respectively, and the average absolute and relative power for females was $435.5 .9 \pm 12.3 \mathrm{~W}$ and $8.4 \pm 0.3 \mathrm{~W} /$ $\mathrm{kg}$, respectively. Absolute maximum power of $705.9 \pm 20.7 \mathrm{~W}$ and relative power of $11.3 \pm 0.2 \mathrm{~W} / \mathrm{Kg}$ for male athletes of the same category and maximum and relative power respectively of $707.9 \pm 14.7 \mathrm{~W}$ and $9.0 \pm 0.2$ $\mathrm{W} / \mathrm{Kg}$ for females ${ }^{23,24}$. As for this test, athletes in the present study showed better performance compared to values previously found in literature, and 
athletes in the senior category showed values statistically higher than the other categories, which can be explained by the intensity and characteristics of the training routines, in addition to the chronological factor.

Flexibility is relevant in TKD, given that it allows the execution of higher and more complex kicks, which are worth more points ${ }^{16}$. Recreational male athletes reach $31.7 \pm 9.7 \mathrm{~cm}$ in the sit-and-reach test, while more experienced athletes reach $39.1 \pm 4.3 \mathrm{~cm}^{18}$. However, female Croatians, medalists in international competitions, have flexibility of $54.8 \pm 4.5 \mathrm{~cm}$, and non-medalists reach $56.6 \pm 5.2 \mathrm{~cm}^{20}$.

The importance of aerobic fitness in TKD performance is related to the faster recovery capacity of athletes between efforts and combats ${ }^{10}$. International-level Tunisian athletes ${ }^{15}$ have $\mathrm{VO}_{2} \max$ of $52.2 \pm 2.57 \mathrm{ml} / \mathrm{kg}$ / min and Perandini et al. ${ }^{25}$ found that Brazilian athletes have $51.9 \pm 2.9$ $\mathrm{ml} / \mathrm{kg} / \mathrm{min}$. Athletes in the present investigation showed lower values, possibly due to the absence of specific sessions to improve aerobic fitness in their training routine and, in this sense, its improvement during the training period is suggested, since Markovic et al. ${ }^{20}$ reported that medalists in world and European championships showed greater cardiorespiratory fitness.

In TKD, abdominal musculature must be well developed, as it helps in rotational movements and in absorbing the impact of kicks throughout the combat ${ }^{7}$. Regarding abdominal resistance, American black belt athletes perform $53.7 \pm 3.2$ repetitions ${ }^{26}$, Puerto Rican Olympic level athletes reach $49.5 \pm 6.1$ repetitions ${ }^{27}$. When compared to data previously found in literature, athletes in the present investigation have lower abdominal resistance level than expected for elite athletes, which is approximately 50 movements in one minute ${ }^{26}$. As for the upper limbs, which are used in the application of punches, in the elbow flexion test, adolescents perform $25 \pm$ 15 repetitions $^{6}$, Olympic level Puerto Ricans reach $52.9 \pm 18$ repetitions $^{27}$ and, in the present study, cadets reached $25.5 \pm 16.8$ repetitions and more experienced individuals reached $31.6 \pm 5$ repetitions. As for handgrip, in a study ${ }^{28}$, elite female athletes reached $34.25 \pm 7.49 \mathrm{kgf}$ and male athletes reached $34.28 \pm 9.06 \mathrm{kgf}$, performances inferior to junior and senior categories of the present evaluation, but not inferior to the cadet category.

As for specific performance evaluations, in a previous study, elite Brazilian athletes performed $23.90 \pm 0.66$ repetitions in the 10 -s test ${ }^{1}$. Among Italian athletes of regional and international level ${ }^{29}$, performance was $20.7 \pm$ 1.6 kicks, although it is indicated that the performance of complex exercise ${ }^{13}$ increases the performance to values of $23 \pm 5$ kicks in 10 s. The results of the present study found no difference between categories regarding the number of kicks performed and value similar to that of other studies was found. The results of the present study reinforce the practical applicability of specific tests to discriminate competitive levels in the sport ${ }^{30}$; however, the results of the evaluated sample are below expectations for high level athletes, which suggests that training sessions with exercises aimed at improving power and kicking speed are necessary, especially if associated with plyometric exercises and manipulation of recovery periods ${ }^{13}$. 
Finally, it is necessary to highlight some limitations that must be considered when interpreting our findings. Among them the cross-sectional design, which does not allow cause and effect inferences. Nevertheless, evidence about the effect of experience on specific performance appear to be consistent with what is expected, and our results can encourage coaches to reinforce attention in specific training sessions. Another limitation refers to the small number of experienced athletes; however, it seems to be difficult to overcome this limitation with the expected pattern of abandonment in combat sports over the practice period.

\section{CONCLUSION}

Men exhibited better performance in vertical jumps; more experienced athletes showed greater power in lower limbs. Graduated men and women perform more abdominal pushup repetitions. Older and graduated men and women have greater anaerobic power. Men presented greater anaerobic power. Younger athletes had lower isometric handgrip strength. Young men and adults have higher $\mathrm{VO}_{2} \max$. More experienced athletes had higher $\mathrm{VO}_{2}$ max than beginners. In specific kick time tests, differences between categories and sex were not identified, but graduation differences were rather found.

In general, when considered together, these results indicate that sex, experience and age group do not affect general physical fitness variables in a similar way, and that experience in the modality seems to influence performance in specific tests.

\section{COMPLIANCE WITH ETHICAL STANDARDS}

\section{Funding}

This research did not receive any specific grant from funding agencies in the public, commercial, or non-profit sectors. This study was funded by the authors

\section{Ethical approval}

Ethical approval was obtained from the local Human Research Ethics Committee - Federal University of Pelotas and the protocol (no. 445.796/2013) was written in accordance with standards set by the Declaration of Helsinki.

\section{Conflict of interest statement}

The authors have no conflict of interests to declare.

\section{Author Contributions}

Conceived and designed the experiments: BFA, AF, FBDV. Performed the experiments: BFA, AF. Analyzed data: BFA, FBDV, VSC. Contributed with reagents/materials/analysis tools: DHF. Wrote the paper: BFA, AF, FBDV, LDC, VSC, RVL. 


\section{REFERENCES}

1. Antunez BF, Palermo Jr J, Del Vecchio AHM, Del Vecchio, FB. Perfil antropométrico e aptidão física de lutadores de elite de taekwondo. Conexões 2012; 10(3): 61-76.

2. Machado SM, Osório RAL, Silva NS, Magini M. Biomechanical analysis of the muscular power of martial arts athletes. Med Biol Eng Comput 2010;48(6):573-7.

3. Campos FAD, Morine D, Avakian P, Fernandes CAM, Aoki MS, Moreira A, Franchini E. Perfil antropométrico de atletas de taekwondo de alto rendimento (Abstract). Anais III Congresso de Ciência do Desporto. Campinas: FEF: 2009.

4. Toskovic NN, Blessing D, Williford HN. Physiologic profile of recreational male and female novice and experienced Tae Kwon Do practitioners. J Sports Med Phys Fit 2004; 44(6): 164-72.

5. Noorul HR, Pieter W, Erie ZZ. Physical fitness of recreational adolescent taekwondo athletes. Braz J Biomotr 2008; 2(4): 230-240.

6. Del Vecchio FB; Franchini E, Del Vecchio AHM, Pieter W. Energy absorbed by electronic body protector from kicks in a taekwondo competition. Biol Sport 2011; 28(1): 75-78.

7. Queiroga MR. Testes e medidas para avaliação da avaliação física relacionada à saúde em adultos. Rio de Janeiro: Guanabara Koogan; 2005.

8. Moreira A, Maia G, Lizana CR, Martins EA, Oliveira PR. Reprodutibilidade e concordância do teste de salto vertical com contramovimento em futebolistas de elite da categoria sub-21. Rev Educ Física 2008; 19(3): 413-421.

9. Heyward VH. Avaliação física e prescrição do exercício: técnicas avançadas. Porto Alegre: Art Med; 2004.

10. Franchini E. Teste anaeróbio de Wingate: conceitos e aplicação. Rev Mackenzie Ed Fís Esporte 2002; 1(1): 11-27.

11. Bangsbo J, Iaia FM, Krustrup P. The yo-yo intermittent recovery test: A useful tool for evaluation of physical performance in intermittent sports. Sports Med 2008; 38(1): 37-51.

12. Wells KF, Dillon EK. The sit and reach: a test of back and leg flexibility. Res Q Exerc Sport 1952; 23(1): 115-118.

13. Santos JFS, Valenzuela TH, Franchini E. Can different conditioning activities and rest intervals affect the acute performance of taekwondo turning kick? J Strength Cond Res 2015; 29(6): 1640-1647.

14. Fernández CB, Majolero VM, Rodríguez JV, González CM. Diferencias en el salto vertical y la velocidad de patada mae-geri entre karatekas internacionales y nacionales. J Asian Martial Arts 2013: 8(1); 13-20.

15. Bouhlel E, Jouini A, Gmada N, et al. Heart rate and blood lactate responses during taekwondo training and competition. Sci Sports 2006; 21(5): 285-90.

16. Heller J, Peric T, Dlouhá R, Kohlíková E, Melichna J, Nováková H. Physiological profiles of male and female taekwondo (ITF) black belts. J Sports Scienc 1998; 16(3): 243-249.

17. Suzana MA, Pieter W. Motor ability profile of junior and senior taekwondo club athletes. Braz J Biomotri 2009; 3(4): 325-331.

18. Toskovic NN, Blessing D, Williford HN. Physiologic profile of recreational male and female novice and experienced Tae Kwon Do practitioners. J Sports Med Phys Fit 2004; 44(2): 164-72.

19. Pilz-Burstein R, Ashkenazi Y, Yaakobovitz Y, Cohen Y, Zigel L, Nemet D, Shamash N. Eliakim A. Hormonal response to Taekwondo fighting simulation in elite adolescent athletes. Eur J Appl Physiol 2010; 110(6): 1283-90.

20. Markovic G, Misigoj-durakovic M, Trninic S. Fitness profile of elite Croatian female taekwondo athletes. Coll Antropol 2005; 29(1): 93-9.

21. Malina R, Bouchard C, Bar-Or O. Growth, maturation, and physical activity. Champaign: Human Kinetics; 2004. 
22. Taaffe D, Pieter W, Yeh K. Short-term muscle power of junior taekwondo athletes. In: International Congress and Exposition on Sports Medicine and Human Performance. 1991; 16-20.

23. Bercades L, Pieter W, Lochner L, et al. Short-term muscle endurance in young taekwondo athletes. 38th World Congress Proceedings. Gainesville: The University of Florida College of Health and Human Performance: 1995, p.167-169.

24. Perandini L, Siqueira-Pereira T, Okuno N, et al. Relationship between vagal withdrawal and reactivation indices and aerobic capacity in taekwondo athletes. Rev Bras Cineantropom Desemp Hum 2010; 12(1): 8-13.

25. Thompson WR, Vinueza C. Physiologic profile of tae kwon do black belts. Sports Med Training Rehab 1991; 3(1): 49-53.

26. Rivera MA, Frontera WR. Health related physical fitness characteristics of elite Puerto Rican athletes. J Strength Cond Res 1998; 12(3): 199-203.

27. Cetin C, Keçeci AD, Erdoğan A, Baydar ML. Influence of custom-made mouth guards on strength, speed and anaerobic performance of taekwondo athletes. Dent Traumatol 2009; 25(3): 272-6.

28. Villani R, Tomasso A, Angiari P. Elaboration of a specific test to evaluate the execution time of the circular kick in Full Contact. Annual Congress of the European College of Sports Science. Clermont-Ferrand, 2004, p.295.

29. Kazemi M, Waalen J, Morgan C, White AR. A profile of Olympic Taekwondo competitors. Sports Sci Med 2006; 5(CSSI): 114-121.

30. Santos JFDS, Franchini E. Frequency speed of kick test performance comparison between female taekwondo athletes of different competitive levels. J Strength Cond Res 2018;32(10):2934-2938.

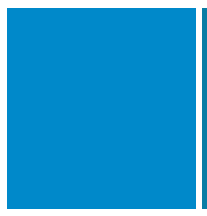

Corresponding author

Andressa Formalioni

Rua Andrade Neves, 2412, 401

CEP: 96020080

Pelotas, Brasil

Email: andressaformalioni@hotmail.com 